\title{
Kearifan Lokal Hamis Batar Suku Manehitu Fafiur di Kabupaten Belu NTT
}

\author{
Frida Tahu' ${ }^{1}$, Augusta De Jesus Magalhaes ${ }^{2}$ \\ Pendidikan Geografi dan Pendidikan Sejarah \\ SMP Katolik Unggulan Santa Maria ${ }^{1}$ dan Universitas Aryasatya Deo Muri Kupang 2 \\ Email: fridatahu28@gmail.com
}

\begin{abstract}
This research aimed to find outthe mechanism of hamisbatar local wisdom of ManehituFafiur Tribe, in Belu Regency, NTT. This study was descriptive qualitative research. Data collection was carried out using observation, documentation and interview. Data analysis was conducted qualitatively encompassing data reduction, data display, and conclusion drawing. The result of research showed that hamisbatar rite was organized in six stages: preparing land rite, planting rite, hamisbatarrite held in Manehitufafiur tribal house, corn harvest rite, corn collection in customary house, and corn binding rite still continue to be implemented until today.
\end{abstract}

Keywords : Hamis Batar, Local Wisdom

\begin{abstract}
ABSTRAK
Penelitian ini bertujuan untuk mengetahui; Mekanisme kearifan lokal hamis batar Suku Manehitu Fafiur,di Kabupaten Belu, NTT. Penelitian ini merupakan penelitian kualitatif deskriptif. Pengumpulan data dilakukan melalui wawancara mendalam, observasi, dan dokumentasi. Analisis data secara kualitatif melalui, reduksi data, penyajian data, dan kesimpulan. Hasil penelitian disimpulkan bahwa upacara hamis batar dapat dilakukan melalui enam tahap yaitu upacara penyiapan lahan, upacara penanaman, upacara hamis batar yang dilakukan di rumah suku Manehitu fafiur, upacara penen jagung, upacara pengumpulan jagung di rumah dan upacara ikat jagung masih terus dilaksanakan hingga saat ini.
\end{abstract}

Kata Kunci : Kearifan Lokal, Hamis Batar 


\section{PENDAHULUAN}

Kearifan lokal merupakan warisan nenek moyang kita dalam tata nilai kehidupan yang menyatu dalam bentuk religi, budaya dan adat istiadat. Dalam perkembangannya masyarakat melakukan adaptasi terhadap lingkungannya dengan mengembangkan suatu kearifan yang berwujud pengetahuan atau ide, peralatan, dipadu dengan norma adat, nilai budaya, aktivitas mengelola lingkungan guna mencukupi kebutuhan hidupnya(Tamalene, Henie, Al, Suarsini, \& Rochman, 2014).

Salah satu bentuk kearifan lokal yang terdapat di kabupaten Belu adalah kearifan lokal Hamis Batar. Kearifan lokal hamis batar dilaksanakan oleh masyarakat Belu sebagai wujud rasa syukur dan terima kasih kepada Sang Pencipta atas panen yang mereka peroleh selama setahun. Pengucapan syukur berupa mempersembahkan jagung ke gereja dan rumah adat. Persembahan itu mempunyai nilai religius dan budaya sehingga para petani selalu melakukan hamis batar untuk mengenangkan dan mengucapkan syukur kepada Tuhan Yang Maha Esa. Jagung muda itu dipersembahkan kepada: 1). Rumah adat tempat penyimpanan alat-alat sakral peninggalan leluhur zaman dahulu, dimana alat-alat itu dipakai oleh nenek moyang untuk perang, bertani, mempertahankan serangan musuh dan serangan lainnya; 2). Tempat-tempat kuburan dimana leluhur itu dikuburkan agar para leluhur tetap mendoakan petani; 3). Sumber air yang merupakan sumber kehidupan manusia yaitu sumber air pemali; 4). Untuk kandang sapi, kerbau, dan kuda (hewan ternak yang besar yang dapat membantu memperlancar kehidupan manusia) dan supaya hewan-hewan itu bisa berkembang biak dengan baik dan terhindar dari serangan penyakit (Neonbasu, 2013).
Hamis batar merupakan kearifan lokal yang hadir dalam sosok peraturan adat yang mempertahankan nilai-nilai lama dalam menjaga kelestarian lingkungan yang sudah berkembang sejak nenek moyang. Hamis Batar dapat memiliki nilai hukum yang berhubungan dengan cara, kebiasaan, tata kelakuan, dan adat yang memuat unsur etika dan norma. Nilai-nilai hukum yang substansial dalam hamis batar sebagai inti dari hukum adat dalam pemeliharaan dan pelestarian alam demi peningkatan kesejahteraan bersama dan mengurangi timbulnya kejahatan berupa kerusakan sumberdaya alam (Manek, n.d.).

\section{METODE}

Penelitian ini merupakan penelitian kualitatif deskriptif. Penelitian ini dilakukan di Kecamatan Raimanuk, Kabupaten Belu Propinsi Nusa Tenggara Timur, yang terletak diantara $124^{\circ} 35^{\prime}$ $126^{\circ} 12^{\prime}$ BT dan $8^{\circ} 57^{\prime}-9^{\circ} 49^{\prime}$ LS dengan luas wilayahnya 179,42 $\mathrm{km}^{2}$. Pengumpulan data dilakukan melalui observasi, dokumentasi, dan wawancara. Analisis data secara kualitatif melalui, reduksi data, penyajian data, dan pengambilan kesimpulan.

\section{HASIL DAN PEMBAHASAN}

\section{Upacara Adat Hamis Batar pada Suku Manehitu Fafiur \\ a) Upacara Pembukaan Lahan Baru}

Masyarakat suku Manehitu Fafiur umumnya adalah masyarakat petani tradisional yang hidup dari berladang di kebun dan sawah. Masyarakat suku Manehitu Fafiur menerapkan sistem gotong royong baik saat membuka ladang baru maupun untuk membersihkan dan memanen hasil kebun. Pembukaan lahan didahului dengan ritual adat untuk menghormati roh tanah dan pohon besar (hatetu harani foho rai - rai bot nain - ai bot nain). Hal ini karena 
kawasan hutan akan dijadikan cikal bakal ladang baru, yaitu memiliki penghuni atau pemilik tanah (Rai Nain). Keyakinan akan adanya tuan tanah yang harus dihormati merupakan pengakuan terhadap kekuatan supranatural. Oleh karena itu, untuk seremoni pembukaan lahan, pada bakal area lahan disebelih seekor kerbau/sapi/babi/ayam sebagai sajian/persembahan. Jenis hewan kurban yang akan disembelih dipengaruhi oleh jenis hutan yang akan dibuka serta banyaknya pekerja yang akan membuka lahan(Si, Sri, \& Pujiastuti, 2015)

Ritus ini dilakukan dengan mempersiapkan terlebih dahulu hewan korban. Setelah hewan korban yang disiapkan dilokasi lahan (biasanya di tengah-tengah area kebun yang telah ditentukan dan dipersiapkan dengan meletakan batu menyerupai gunung), disiapkan sirih dan pinang masing-masing 3 atau 7 lembar sirih dan lempengan pinang. Dengan memengang sehelai daun siri atau satu irisan pinang. Tua adat kemudian melakukan usap $(s a, u)$. Daun siri dan pinang diusapkan ke tubuh hewan korban sebanyak tiga kali, dengan mengucapkan doa.

Bagi kebayakan masyarakat lokal suku Manehitu Fafiur menggangap bahwa alam adalah realitas sesungguhnya dan merupakan sebuah analogi bagi hidup bermasyarakat. Hal ini karena hukum adat dilihat sebagai warisan para leluhur yang mengatur hidup dan wajib diturunkan untuk generasi yang akan datang (Neonbasu, 2013)

\section{b) Ritual Adat Sebelum Proses Penanaman Benih Tanaman}

Beberapa ritual adat sebelum menanam benih pada area lahan dilakukan beberapa upacara adat diantaranya menyusun mesbah persembahan dari batu ditengahtengah ladang (Hada taroman). Mesbah ini disusun dari batu dan bambu yang panjang beberapa ruas. Mesbah tersebut di tengah-tengah ladang yang disusun dari batu yang pipih dan lebar, juga ditanam salip sebagai wujud penghormatan Allah Tritunggal Maha Kudus(Henschke \& Ratana-ubol, 2015).

Pada hanekmatan dan taroman diletakan sirih satu lembar (fuik tahan ida), pinang 1 lempeng (bua klaut ida), serta benih jangung dan tanaman lain yang akan ditanam. Sirih dan pinang sebanyak 1 menggambarkan pengakuan akan Allah yang satu. Setelah sirih pinang diletakan pada hanekmatan sebanyak 7 buah, hewan kurban (babi, kambing, atau ayam), diusap dengan sirih satu lembar (proses $s a^{\prime} u$ ). setelah $s a^{\prime} u$, hewan yang dibawa disembelih dan darahnya dipercikan diatas taroman, sirih dan pinang dalam hanekmatan serta diteteskan pada au bonun ida yang berisi air. Pencampuran antara air dan darah hewan kurban, diyakini akan membuat jagung bertumbuh subur (Neonbasu, n.d.-b)

\section{c) Upacara Penanaman Benih}

Pada tahap berikutnya adalah benih ditanam secara simbolis pada 3 titik tanam (ahuk lotu), yang letaknya mengelilingi taroman dengan mata tertutup. Tiga lubang untuk menanam jagung sambil menutup mata, dilakukan sebagai bentuk penghargaan dan penghormatan terhadap: a. Maromak (dalam iman katolik dikenal dengan Allah Tritunggal Maha Kudus), b. Bumi dan sekitarnya (Raiklaran) untuk menghormati pemilik air (We Nain), pemilik tanah dan gunung (Rai No foho Nain), serta lelulur (Bei Sia), c. 
manusia (Ema) dalam perspektif tiga pola hubungan yang keramat, yang tidak boleh dilakukan untuk meneruskan kehidupan manusia sehingga harus dijaga dan di hormati, yakni hubungan bapak dan anak kandung, ibu dengan anak kandung, serta antara kakak dan adik kandung(Neonbasu, n.d.-a).

\section{d) Upacara Pemanenan jagung (hamis batar)}

Menurut adat yang berlaku, sebelum hasil pertanian (jagung) tersebut dipanen dan dikomsumsi, harus dilakukan upacara panen sebagai ungkapan syukur atas hasil panen yang diperoleh. Serimonial adat ditunjukan kepada simpul-simpul keyakinan seperti, kelakuan supranatural di rumah adat (uma lulik), roh air (We naini), pengusaha bumi (foho rai bot nain), alat menanam (mudak), roh leluhur (mate bian) (Neonbasu, 2013). Mekanisme hamis batar dibagi atas tiga tahap yaitu:

a) Tahap Persiapan

Sebelum dilakukan hamis batar setiap pemilik kebun supaya mempersiapkan jagung yang akan dibawa ke rumah adat untuk hamis batar, dengan klasifikasi jagung berupa: 1). Ada rambutnya untuh, 2). Jagung tidak memenuhi syarat disisihkan, 3). Bulir jagung berjumlah empat buah, 4). satu rumpun jagung yang akan dimasukan kedalam rumah adat, dicabut lengkap dengan akarakarnya dan dibawa kedalam rumah adat untuk diikat pada kakuluk lor (laki-laki) yang ada bagian atasnya digantung berbagai benda sakral atau keramat milik suku. 5). Setiap pemilik kebun, membawa jagung ke rumah (12 pulir atau 7 pulir jagung) kedalam rumah adat (Tama Tuir). Jagung di rumah ini akan dimasak dan dibagibagi kepada setiap anggota suku untuk dimakan bersama sebagai tanda bahwa hamis batar telah dilakukan. 6). Anggota suku perempuan membawa alat tenun dan kelengkapan menanam, dan anggota suku laki-laki membawa parang dan kapak, untuk didinginkan melalui semburan sirih dan pinang.

\section{b) Di Tengah Kebun}

Upacara yang dilaksanakan di mesbah persembahan (Taroman). Tujuan dari ritual hamis batar yaitu sebagai ungkapan terima kasih kepada leluhur, pemilik tanah, pemilik/roh jagung, dan pemilik air (foho nain, rai nain, batar nain no we nain). Kepercayaan yang dibangun dari ritual ini, agar roh jagung tidak meninggalkan lahan (batar nain keta sae nela) sehingga produktivitas jagung yang akan dipanen tidak berkurang.

c) Upacara hamis batar Di Dalam Rumah Adat (Uma Lulik)

Upacara hamis batar juga dilaksanakan di dalam rumaha adat. Jagung persembahan sejumlah tangkai jagung (Batar liman) yang ada di Taroman, dibawa ke dalam rumah adat dan diikat ke tiang agung pertama (kakuluk mane), dan jagung yang baru di panen setiap warga suku, diletakan di tiang agung kedua (kotan kakuluk feto), empat sudut (sikun hat) rumah adat sebagai simpul keyakinan terhadap eksistensi empat penjuru angin, tungku masak (lalian), pintu rumah (oda matan), tempat pertemuan keluarga (leo laran), dan tempat pemujaan (foho). Tiap henematan diisi dengan sirih pinang dan jagung. Penyiapan Henematan sebanyak 12 buah berkorelasi dengan 12 rasul. Setelah semua henematan sesuai dengan tujuan disiapkan dan 
lengkap, ritual adat diawali dengan doa.

Momentum ini untuk mengevaluasi beberapa hal yaitu: 1). Menurunkan benda-benda keramat peninggalan leluhur, untuk ditunjukan kepada semua anggota suku. 2). Rekonsiliasi antar sesama anggota suku sehingga menjadi momentum refleksi antara warga suku, apabila selama ini terdapat hubungan yang renggang akibat ketersinggungan, salah kata, salah tindak dan konflik, sehingga hamis batar menjadi saat pemulihan kembali relasi yang tidak harmonis tersebut (Neonbasu, 2013).

\section{KESIMPULAN}

Hamis batar merupakan bagian dari kearifan lokal dari masyarakat Belu. Kebiasaan bertani bagi masyarakat suku Manehitu Fafiur tidak dapat dipisahkan dari ritus penghormatan terhadap nenek moyang. Proses dalam hamis batar meliputi beberapa tahap yang dimulai dari penyiapan ladang, penanaman benih, serta upacara hamis batar disertai dengan penyembelihan hewan korban dalam kepercayaan masyarakat lokal tersebut. Upacara hamis batar dapat menggabungkan ritual adat istiadat dengan sistem pertanian, sehingga muncul kesadaran bagi masyarakat untuk tetap menjaga dan melestarikan alam dan budaya lokal untuk generasi yang akan datang.

\section{DAFTAR PUSTAKA}

Eidinow, E., n.d. Telling stories: Exploring the relationship between myths and ecological wisdom.

Henschke, J.A., Ratana-ubol, A., 2015. Cultural Learning Processes through Local Wisdom: A Case Study on Adult and Lifelong
Learning in Thailand. doi:10.4018/ijavet.2015040104

Jayadi,Yanuwiad, Purnomo, E., Soemarno,Bagyo, Mangku, n.d. Local Wisdom Transformation of Wetu Telu Community on Bayan Forest Management, North Lombok, West Nusa Tenggara. 2014 Vol.4, No.2,2014.

Jitsanguan, T., n.d. sustainable Agricultural Systems for SmallScale Farmers In Thailand:Implications For The Enviroment 11.

Manafe, Y.D., n.d. Komunikasi Ritual pada Budaya Bertani Atoni Pah Meto di Timor-Nusa Tenggara Timur 287298.

Manek, V., n.d. Ema Tahakae Sisi (sebuah tamasya ke akar asal di gunung lakaan dan etika hidup kumunitas Adat kobalima di Belu-Timor. Gita kasih 2015, kupang.

Mungmachon, M.R., 2012. Knowledge and Local Wisdom: Community Treasure. Int. J. Humanit. Soc. Sci. $2,174-181$.

Neonbasu, G., 2013. Kebudayaan Sebuah Agenda Dalam Bingkai Pulau Timor dan sekitarnya, 1st ed. PT Gramedia Pustaka Utama, Jakarta.

Neonbasu, G., n.d. Citra manusia Berbudaya, Pertama. ed. Antara Publishing, Jakarta.

Neonbasu, G., n.d. Akar Kehidupan Masyarakat Sumba Dalam Cita Rasa Marapu. Lappop PressJakarta, Jakarta.

Prasetyo, A., n.d. Peran Kearifan Lokal Dalam Menjaga Kelestarian Hutan. 
Si, M., Sri, R., Pujiastuti, E., 2015. Scientific Knowledge Based Culture and Local Wisdom in Karimunjawa for Growing Soft Skills Conservation 4, 598-604.

Simanjuntak, E.R., n.d. kearifan Lokal Pengelolaan Hutan Oleh Masyarakat Sekitar Kawasan Tanaman Wisata Alam Sicike-Cike, Sumatera Utara.

Sumarmi, S., 2015. Local Wisdom of Osing People in Conserving Water Resources. Komunitas Int. J. Indones. Soc. Cult. 7, 43. doi:10.15294/komunitas.v7i1.342 9

Tamalene, M.N., Henie, M., Al, I., Suarsini, E., Rochman, F., 2014. The Practice of Local Wisdom of Tobelo Dalam ( Togutil ) Tribal Community in Forest Conservation in Halmahera , Indonesia. Int. J. Plant Res. 4, 1-7. doi:10.5923/s.plant.201401.01

Windari, T.R.I., I, R.M.A.R., 2013. The Practice of Local Wisdom of Dayak People in Forest Conservation in South Kalimantan 1, 37-46.

Yunita, n.d. Developing Local Wisdom as the Basic of Integrated Extension Model in Paddy Cultivation at Lowland Ecosystem in South Sumatra. Proc. 2012 Int. Conf. Biotechnol. Environ. Manag. ICBM 2012. 